Article

\title{
When a Girl Awakened the World: A User and Social Message Analysis of Greta Thunberg
}

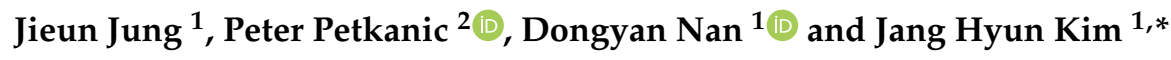 \\ 1 Department of Interaction Science, Sungkyunkwan University, Seoul 03063, Korea; \\ jungjieun012@gmail.com (J.J.); ndyzxy@gmail.com (D.N.) \\ 2 Department of Big Data Engineering, Vrije Universiteit Amsterdam, 1081 HV Amsterdam, The Netherlands; \\ petkanic.peter@gmail.com \\ * Correspondence: alohakim@skku.edu
}

Received: 11 February 2020; Accepted: 25 March 2020; Published: 30 March 2020

\begin{abstract}
Young climate activist Greta Thunberg was Time magazine's Person of the Year for 2019. In this study, the authors examine the role of social media in Thunberg's rise to prominence by investigating Twitter communications over 14 months, analyzing tweet contents and user profiles. The changes in sentiment revealed on Twitter are examined, along with four major events from the period. The paper also compares Swedish and American user characteristics in relation to Thunberg. The findings reveal that celebrities and public figures played an essential role in amplifying the influence of the activist. To categorize the influencer group, the authors identified each user's occupation, organization, location and position on other social issues. The results show that some people held a negative attitude toward Thunberg, not only because of their skepticism about climate change but also because of their views on other social issues, such as gender and age.
\end{abstract}

Keywords: Greta Thunberg; environmental movements; climate change; social media; Twitter; sustainability; media analysis

\section{Introduction}

In 2018, Sweden went through the hottest summer since records began 262 years ago and many wildfires occurred throughout the country [1]. Fifteen-year-old Greta Thunberg began protesting to draw attention to the climate crisis by sitting in front of the Swedish parliament. She refused to go to school until Sweden's general election day, 9 September 2018 [2]. She started the protest alone, but her school strike went viral and became a worldwide phenomenon. On 15 March 2019, an estimated 1.6 million students from over 120 countries joined the school strike for the climate [3].

Thunberg had become a global icon of the climate movement by the time of her impassioned speech at the United Nations Climate Action summit on 23 September 2019, and the speech was widely covered as headline news. Her rapid rise to world fame made her a leader and a target at the same time.

Thunberg is not the first young climate activist with a high profile [4], but few of her predecessors had had the same kind of sustainable and disruptive effect. The "Greta effect" [1] began to inspire teenagers in climate activism and managed to influence groups of people who had not previously seemed to be interested in her agenda. Austria's Green Party won 10\% more of the vote than in the previous election thanks to people being inspired by Greta's actions [5], and the British band Coldplay brought its world tour to a stop until it could find a way to perform in a sustainable way [6].

While Greta posted her original strike photo on both Instagram and Twitter, her earliest high-profile supporters, who helped her action to spread further, were on Twitter [7]. She also understood social media and was clever enough to utilize her Twitter bio in response to the people who trolled her [8]. 
As of February 2020, Thunberg had 4 million followers on Twitter and 9.7 million followers on Instagram. She is thus able to speak to the world directly. The authors believe that it is important to identify the dynamics of social media communication to find out how this teenage activist has been able to reach the entire world in such a short period. There has been a body of literature about the role of social media; some of them have focused on the polarization of environmental debates, but few have focused on the activists themselves.

\section{Literature Review}

\subsection{Diffusion of Issues on Social Media}

Social media have a variety of users, including lay people, celebrities, entrepreneurs, politicians-even presidents of countries. Therefore, topics from diverse social and interest groups come together on social media [9]. Twitter's audience profile is relatively balanced in terms of demographics, particularly gender and age, compared to other social media [10].

Twitter encourages its users to share "what's happening," making it a source of reporting and a news channel at the same time. According to the study by Shearer and Grieco, up to $55 \%$ of US adults sometimes or often use social media as their news source [10]. However, more than $80 \%$ of social media news consumers have concerns about one-sided and inaccurate news; $48 \%$ think that the news posted on social media generally has a more liberal bias than conservative [10]. Nonetheless, Twitter has been rapidly adopted by journalists as an essential source of news items and information. Using social media as an information source may be convenient and effective [11].

Lerman and Ghosh have explained how issues travel on Twitter. First, Twitter users create social networks by following other accounts. Second, they use these networks to retrieve and disseminate information. In this way, Twitter users share their friends' social activities with their own followers through their tweets [12]. Geva et al. have pointed out that users can also "retweet," meaning that they can disseminate exact copies of content almost effortlessly. Retweets allow users to utilize someone else's self-expression to link to their own [13]. The reach of an issue thus does not depend solely on individuals disseminating their own ideas [14].

\subsection{Polarization over Climate Change on Social Media}

There has been a variety of research on climate change discussion in social media. Studies have examined the relationship between sentiment and the probability of retweeting [15], the dependence upon traditional media during discussions [16] and networks of users and their tweet topics [17], among other topics. Mutz indicated that contentious issues such as climate change are more likely to activate political polarization [18,19]. Polarized discussions feature two big groups, with little conversation between the two groups [20]. The self-selection of partisan information sources reinforces the polarization [21].

A sense of belonging may lead people to regard opposing remarks as an attack on their identity, and their negative attitude toward their political opposition increases [22]. This negative feeling sometimes ignites hate speech, often directed at minorities. Llewellyn et al. reported that online hate speech may not necessarily be a crime, but it still harms people of different races, religions, disabilities, sexual orientations, ethnicities and genders [23].

\subsection{Sentiment Analysis}

Sentiment analysis is a computational research technique that uses machine learning methods, such as natural language processing and statistic models, to classify texts into the categories of negative, positive or neutral feelings - or to measure the strength of feeling [24] in a large-volume text dataset. In other words, it is a computational approach to assessing the opinions and emotions revealed in texts.

It is well known that texts with positive sentiment are easier to classify than negative ones are $[25,26]$ because positive expressions have more uniformity [27] and higher discriminant value [26] 
than do negative ones, which use extensive expression of negations, have different valence shifters and satirize an object by subverting emotions [24].

There are multiple sentiment analysis tools for identifying words' contextual polarity. TextBlob Sentiment Classifier [28] is a Python [29] library for processing text data that utilizes a Naive Bayes classifier trained with unigram features, as implemented in the Natural Language Toolkit (NLTK) [30]. The tokenizer of the library uses an unsupervised algorithm to build a model for abbreviated words and words that start sentences for finding sentence boundaries. In natural language processing, the performance of classifiers depends heavily on the nature of the domain because they have been trained within specific domains. In the study by Arque et al., TextBlob showed a better performance for the Twitter domain than others, which were better adapted for other domains [31].

Pang and Lee also pointed out that one limitation of sentiment analysis is that domains have a strong impact on its performance [24]. Words considered positive in one domain can be considered negative in another. Moreover, the classifier shows low performance on sarcasm. The objective of sentiment analysis is to cope effectively with a huge dataset and to obtain insights, rather than achieve perfect classification of all data points.

\subsection{Research Questions}

(1) How have Twitter users expressed their perceptions of and sentiments about Greta Thunberg over time, according to word and sentiment analysis?

(2) What are the characteristics of the US and Swedish users on Twitter who are sharing, retweeting, following and commenting on Greta Thunberg?

(3) What are the characteristics of the most followed users and the most shared tweets?

\section{Materials and Methods}

\subsection{Data Collection}

To ensure that the dataset was collected without bias and to reflect public opinion as accurately as possible, several approaches to data acquisition were carefully examined. The Twitter Application Programming Interface (API) provides an efficient and fast way to retrieve substantial amounts of Twitter data because it returns well-formatted JavaScript Object Notation (JSON) which is a lightweight data-interchange format, but it returns random samples. Crawling data directly from the HTML responses of websites is not the fastest way but a very reliable one. After trying several crawling codes and analyzing portions of the returned data for each given time, the authors were able to determine a method for crawling data directly from Hypertext Markup Language (HTML) responses using Python.

Using hashtags runs the risk of losing valuable data because not every tweet has hashtags. This study used Twitter's advanced search (Twitter.com/search-advanced) to specify mentioned keywords instead of hashtags. The sole query keyword, "Greta Thunberg," produced fair and comprehensive results.

The target period was from August 2018, when Greta made her first protest, until the end of October 2019. The study targeted tweets only in English for precise sentiment analysis results. Since the research focused on the users tweeting about Greta, the authors retrieved the user information as well. With these settings, around 1000 tweets per every 80 seconds could be downloaded. To speed things up, the cloud computing platform, Amazon Web Services (AWS) was used to split the workload by date ranges to each of the six virtual machines. The list of information retrieved from a tweet is shown in Table 1.

In total, 1,744,446 tweets were collected. Emojis, emoticons, non-American Standard Code for Information Interchange (ASCII) characters and stop words were removed before tokenizing. With the data ready for analysis, the authors used a combination of quantitative and qualitative analyses of the tweet contents. By setting up meaningful data categories, the authors were able to transform the 
unstructured information in the tweets and user profiles to a structured one to serve the purposes of the analysis.

Table 1. List of information retrieved from a tweet.

\begin{tabular}{ccc}
\hline Type & Description & Example \\
\hline Date & Tweet created date & 23-09-2019 \\
\hline \multirow{2}{*}{ Tweet } & Tweet content & Greta Thunberg is a climate hero \\
& Hashtag & \#ThisIsZeroHour \\
& URL(s) & https://time.com/collection/...../ \\
\hline \multirow{2}{*}{ User Profile } & Name & WeDontHaveTime0 \\
& Display name 1 & We Don't Have Time \\
& Display location ${ }^{1}$ & Near you \\
& User description ${ }^{2}$ & Climate and environmental activist \\
Counts & Tweet language & English \\
\hline Likes, retweets, followers & 491, 34298, 52061
\end{tabular}

${ }^{1}$ User can choose display name and display location as they wish. ${ }^{2}$ Self-disclosure in free text (includes URLs, user mentions, hashtags, etc.).

\subsection{Categorization of Information}

The Twitter API has an option to retrieve "geo-tagged" tweets. This provides the specific location of the tweet users from Global Positioning System (GPS)-enabled devices. However, as retweets do not have location information, this study did not use the Twitter API. Instead, the study relied on users' "display location," which is a self-claimed location in the user information section on the user profile page. Of the total, $71.5 \%$ of tweets had a "display location," sufficient to produce meaningful results.

By grouping users' display locations, the authors were able to identify similar patterns in users' inputting of location. Examples are listed in Table 2.

Table 2. Location patterns and examples.

\begin{tabular}{cc}
\hline Pattern & Example \\
\hline country name & United States/USA \\
\hline city name, country name & London, England \\
\hline city name, state abbreviations & Washington, DC \\
\hline city name or state name & London/Florida \\
\hline others & Planet Earth \\
\hline
\end{tabular}

To determine the location, the authors created a list of countries, states and cities and their abbreviations, as well as their native language notations. By comparing the patterns of display location to this list, the authors were able to determine $58.6 \%$ of the tweets' locations.

The field "user description" is a self-disclosure item in the form of free text, through which users can express themselves. This field offers a lot of interesting information about users. For a quantitative analysis, this study categorized some of the tokenized words and extracted structured information. Users often disclose their occupational information clearly. Sometimes, they write what they believe in or which organizations they support. Some of them write about their birthplace. Similar information can be observed from hashtags.

Many of the tweets have links to external sources of information. The retweet option allows you to post tweets with a Uniform Resource Locator (URL). The analysis revealed that $27.4 \%$ of all tweets contained at least one URL. Consequently, the authors were able to determine the source of information for news shared on Twitter. Table 3 shows the information category, source and examples extracted from tweets. 
Table 3. Categorization of information extracted from tweets.

\begin{tabular}{ccc}
\hline Information Category & Source & Example \\
\hline location & $\begin{array}{c}\text { display location } \\
\text { user description }\end{array}$ & $\begin{array}{c}\text { I study Mathematics at Åbo Akademi, Turku, } \\
\text { Finland }\end{array}$ \\
\hline occupation & user description & $\begin{array}{c}\text { Business Admin, HR Manager. Politics, news, } \\
\text { science, travel, global issues }\end{array}$ \\
\hline religious/political orientation & user description/ hashtag & Naturalist, Conservationist/\#MAGA ${ }^{1}$ \\
\hline source of information & URLs in tweet contents & $\begin{array}{c}\text { Fox News apologized to 16-year-old Swedish } \\
\text { climate activist Greta Thunberg after a guest } \\
\text { called her "mentally ill" } \\
\text { https://cnn.it/2mMN3yy [32] }\end{array}$ \\
\hline
\end{tabular}

${ }^{1}$ Make America Great Again, a political slogan used by Donald Trump.

\section{Results}

\subsection{Descriptive Statistics}

Altogether, 588,479 unique users generated a total of 1,744,446 tweets for 14 months from 20 August 2018. Descriptive statistics about the tweets, including the query "Greta Thunberg," are presented in Table 4.

Table 4. Descriptive Statistics of tweets about Greta Thunberg.

\begin{tabular}{cc}
\hline Data & Statistics \\
\hline period & 14 months \\
& 20 August $2018-31$ October 2019 \\
\hline number of tweets & $1,744,446$ \\
\hline unique users & 588,479 \\
\hline$\%$ having a user description & $85.3 \%$ \\
\hline$\%$ displaying location & $71.5 \%$ \\
\hline$\%$ with hashtags & $18.7 \%$ \\
\hline$\%$ with URLs & $27.4 \%$ \\
\hline Sentiment Analysis & Positive: $44 \%(762,170)$ \\
\hline
\end{tabular}

A surge in tweets occurred on 23 September 2019, when Greta gave a speech at the United Nations (UN) Climate Action Summit. The peak for this day was so high that other events seem relatively unimportant, but there are several spikes.

Figure 1 shows the distribution of tweets and followers. When there were major events related to Greta Thunberg, both the number of tweets and the number of followers of the account @Greta Thunberg increased [33]. Although the number of new followers mostly surpassed the number of tweets, the two presented a similar distribution. Therefore, it is meaningful to analyze the number of new tweets and new followers to capture the dynamics around this topic. 


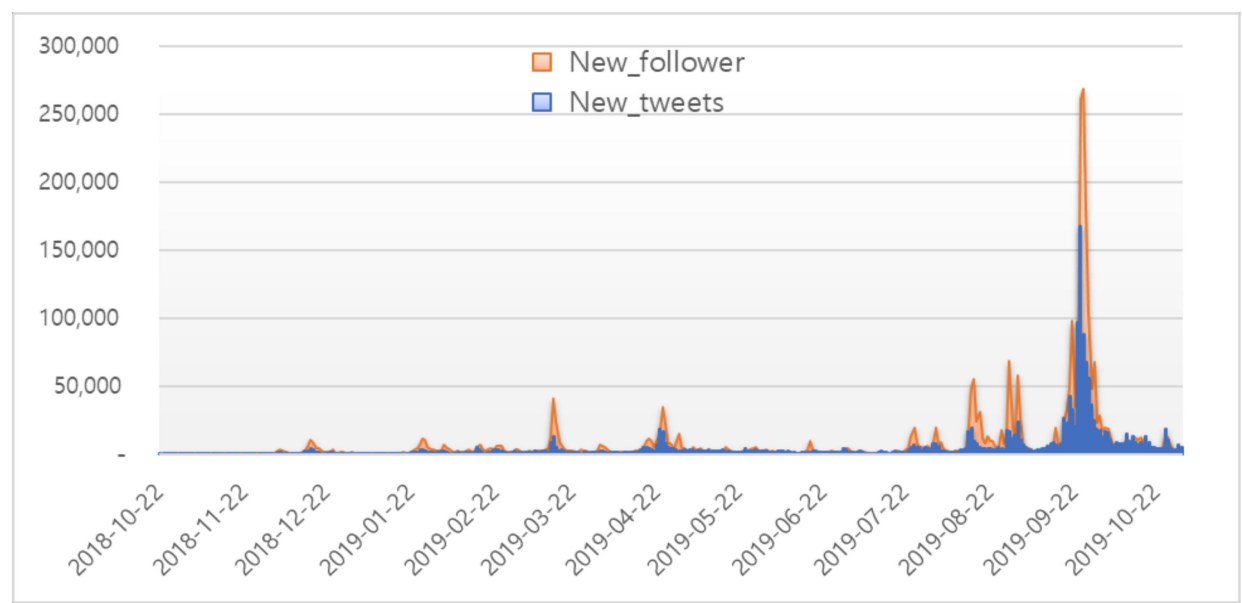

Figure 1. Trend of followers and tweets, October 2018-October 2019. Note: The data from August to September 2018 were so few in number that they were omitted from the analysis.

\subsection{Tweet Content Analysis}

\subsubsection{Sentiment Analysis}

This study used TextBlob because it performed well for the Twitter domain [31]. Using TextBlob, Table 5. 0 (negative) to 1.0 (positive). Of the tweets analyzed, 762,170 (44\%) tweets were positive, $332,540(19 \%)$ were negative and the rest were neutral.

Table 5. The most frequent words for four exemplary categories.

\begin{tabular}{ccc}
\hline Category & Positive & Negative \\
\hline Audience & young people, world leaders & world leaders, young people \\
\hline Appellation & young lady, young woman & little girl, child \\
\hline Related topic & $\begin{array}{c}\text { Nobel Peace Prize } \\
\text { full speech } \\
\text { save planet }\end{array}$ & $\begin{array}{c}\text { George Soros } \\
\text { Andrew Bolt }\end{array}$ \\
\hline $\begin{array}{c}\text { Supportive/discouraging } \\
\text { expressions }\end{array}$ & good luck, well done, & Donald Trump \\
\hline
\end{tabular}

The words "change," "people," "world," "need," and "young" were the most frequent unigrams. In terms of bi/trigrams, "world leaders," "young people," "global warming," and "Nobel peace prize" were the most frequent. After classifying the sentiments of tweets, the 20 most frequent words for both sentiments were extracted. As shown in Table 5, "young people" and "world leaders" were key words in both positive and negative emotions. Meanwhile, other categories revealed the mixed feelings of users.

The appellations in positive tweets showed a certain level of respect, with the words "lady" or "woman" being used, whereas negative tweets used the term "little girl" or "child." Both sentiments were related to global warming but in different contexts. The positive tweets discussed the "Nobel peace prize," recommended watching the "full speech," or voiced "save the planet" sentiments. In negative tweets, George Soros was often mentioned, in phrases such as "George Soros' granddaughter" and "puppet of George Soros." Andrew Bolt, an Australian columnist who labeled Thunberg as "deeply disturbed," "freakishly influential," and "strange," also appeared, as did Donald Trump, who is well known for denying climate change and shared a clip of her speech to a United Nations climate summit with sarcastic commentary. 
The positive tweets expressed support and approvals by saying "good luck," "well done," or "good work." By contrast, the negative tweets treated the event as "child abuse" and thought that Thunberg should go "back to school."

\subsubsection{Tweets Distribution for Four Major Events}

The life span of social media topics may vary substantially, depending on the media platform and the popularity of the topic. In addition, the definitions of topic persistency are diverse [34]. In the dataset of this study, there were fewer than 10 remarkable peaks of tweets generated for important events related to Greta Thunberg. The authors decided to define the "tweet life span" as a period running from the date on which the event occurred to the date on which the peak faded away. The average length of tweet life span was eight days in the dataset.

The authors selected four events that attracted the most followers and generated the most tweets, as shown in Figure 2. To see how each event attracted followers and tweets, the study tracked its trend over the eight days from the day that the event happened and the most frequent words during each period is shown in Table 6.

(1) "2018-12-12": Delivered a Speech at the 24th session of the Conference of the Parties (COP24), the 24th Conference of the Parties to the United Nations Framework Convention on Climate Change At this stage, the followers started to increase slowly as the speech at COP24 was shared. It took four days to reach its peak. Most of the frequent words were from her own speech.

(2) "2019-03-14": Nominated for the Nobel Peace Prize. The school strike went global on March 15. In this period, two meaningful events occurred. The number of tweets and followers rapidly increased and the trend did not last longer than three days, making the spike relatively sharp.

(3) "2019-08-13 to 2019-09-03": Sailed to New York to attend the UN Climate Summit on a zero-carbon yacht. The trans-Atlantic voyage continued for two weeks and was expected to have two peaks, one for the departure and another for the arrival on August 28. Instead, there was another spike a few days after her arrival, so the period was extended to identify its cause. The first peak showed wishes for a safe trip and lasted a while because Thunberg occasionally posted about the journey. Interestingly, comments about Brexit increased. Many people who hated Thunberg were pro-Brexit. The second peak, upon Thunberg's arrival in New York, lasted a short time, making a sharp spike. As the followers and tweets increased, negative attitudes were expressed in a blunt manner (e.g., sick, stupid, mentally unstable, disturbed). In response to these comments, Thunberg tweeted to her followers about ways to deal with "haters" with dignity, as shown in Figure 3. This tweet turned out to be the most influential in our dataset, with over 131,000 retweets and over 800,000 likes.

(4) “2019-09-23." Speech at UN Climate Summit. The tweets about Thunberg's speech at the UN Climate Summit continued over several days, producing a huge, flat peak. The most frequently used words in positive sentences during this period seem to have been extracted from the speech itself. Media coverage of the speech was widespread, and users cited the speech or the media. Consequently, the language used in the speech overwhelmed other comments. 


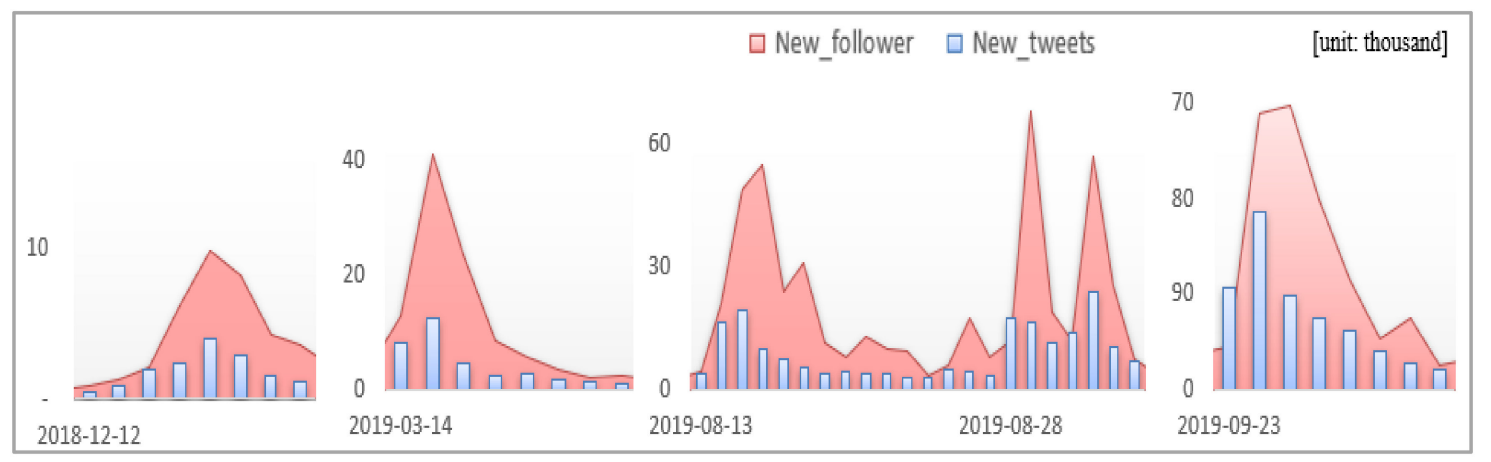

Figure 2. Distribution of tweets from four major periods.

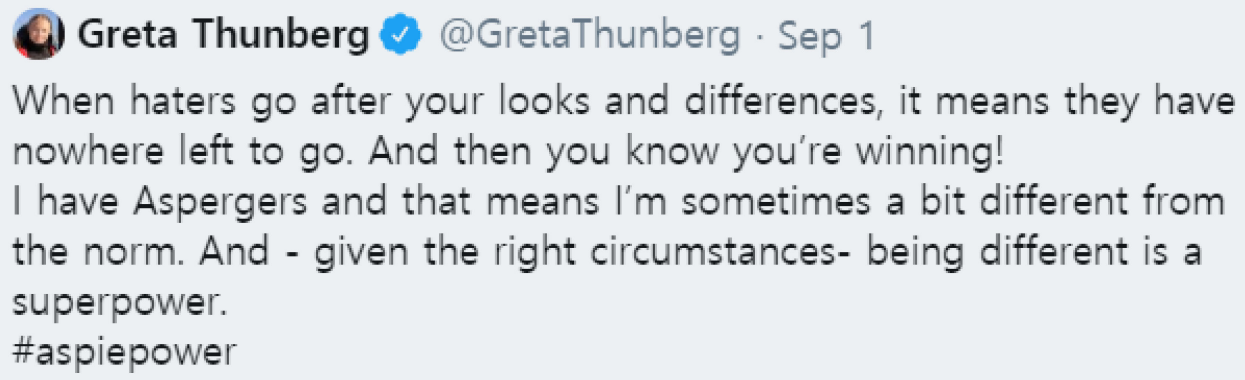

Figure 3. The most shared and liked tweet [35].

Table 6. The most frequently used words during four major periods.

\begin{tabular}{|c|c|c|c|c|c|}
\hline Polarity & $\begin{array}{c}\text { Speech at COP } \\
24\end{array}$ & $\begin{array}{c}\text { Nobel Prize } \\
\text { Nomination, Global }\end{array}$ & \multicolumn{2}{|c|}{ Trans-Atlantic Voyage } & UN Summit Speech \\
\hline Positive & $\begin{array}{l}\text { Young lady } \\
\text { Nobel peace } \\
\text { Full speech } \\
\text { Well done }\end{array}$ & $\begin{array}{l}\text { Nobel peace } \\
\text { Well done } \\
\text { School strike } \\
\text { Demand action }\end{array}$ & $\begin{array}{l}\text { Safe travel } \\
\text { Across the } \\
\text { Atlantic } \\
\text { Confront Brexit } \\
\text { Zero carbon }\end{array}$ & $\begin{array}{c}\text { Arrive NY } \\
\text { Teen activist } \\
\text { Keep going } \\
\text { Alexandria } \\
\text { Ocasio-Cortez }\end{array}$ & $\begin{array}{l}\text { Climate Action } \\
\text { Summit } \\
\text { Economic growth } \\
\text { Mass extinction } \\
\text { Stay strong }\end{array}$ \\
\hline Negative & $\begin{array}{c}\text { Little girl } \\
\text { Child abuse } \\
\text { Andrew Bolt } \\
\text { Back to school }\end{array}$ & $\begin{array}{c}\text { Noble peace } \\
\text { Michael Knowles } \\
\text { Waste of time } \\
\text { Behind science }\end{array}$ & $\begin{array}{l}\text { Zero carbon } \\
\text { Arron Banks } \\
\text { Waste time } \\
\text { Paint saint of } \\
\text { stupidity }\end{array}$ & $\begin{array}{l}\text { Mentally unstable } \\
\text { Autistic people } \\
\text { Deeply disturbed } \\
\text { Child abuse }\end{array}$ & $\begin{array}{l}\text { Little girl } \\
\text { Choose to fail } \\
\text { Child abuse } \\
\text { Donald Trump }\end{array}$ \\
\hline
\end{tabular}

\subsection{User Profile Analysis}

\subsubsection{User Analysis by Country}

The country categorization was conducted using the information from the display location and user description fields; $71.5 \%$ of the accounts had location information. Figure 4 shows that English-speaking countries accounted for the most tweets, which was expected because the data had English tweets only. 


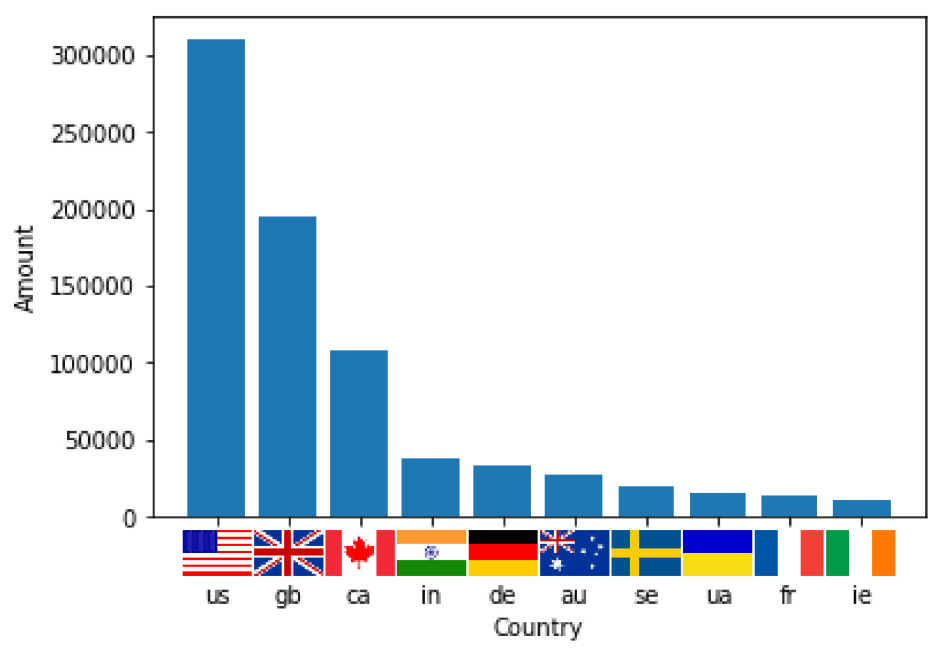

Figure 4. Number of Tweets by country.

Grouping the locations revealed the characteristics of user profiles from diverse countries. The authors decided to compare the information retrieved from user profiles and hashtags of two countries, namely, the United States and Sweden. Sweden is Thunberg's home and the United States represents $22 \%$ of all tweets in the dataset. The authors believe that a comparison of the users of these two countries is meaningful because it would reveal how the tweet conversation and participants changed as the message went global.

\subsubsection{Comparison of the User Profiles of Sweden and the United States}

The user profiles from both countries showed a similar portion of polarity. Roughly $60 \%$ of people from both countries tweeted in a positive way about Thunberg. Since the polarity algorithm is limited in its accuracy [24] and the comparison between users who use English as a native language and as a second language would not be fair, this comparison focused more on the information collected from user profiles of those who tweeted about Greta Thunberg than on the analysis of the tweet contents.

To make a straightforward comparison, the authors used the word cloud generator in the Python package as a visualization aid; the generator provides statistical overview by correlating font size and word frequency [36]. The authors believe that it is suitable to use straightforward visualization of remarkable words in a comparison of the two countries given the users' languages.

As shown in Figure 5, 18.7\% of tweets had hashtags; the differences between the two countries were notable. Greta Thunberg was referred to in more of a political context by Americans than by Swedish users, as opposed to her role in the climate movement. For the United States, election-related hashtags, such as \#MAGA ("Make America Great Again"), \#RESIST, \#TRUMP2020 and \#KAG ("Keep America Great") were the most salient. For Sweden, by contrast, many users used the hashtags \#FRIDAYSFORFUTURE and \#CLIMATESTRIKE, showing that the agenda of climate change set by Thunberg was influential. 


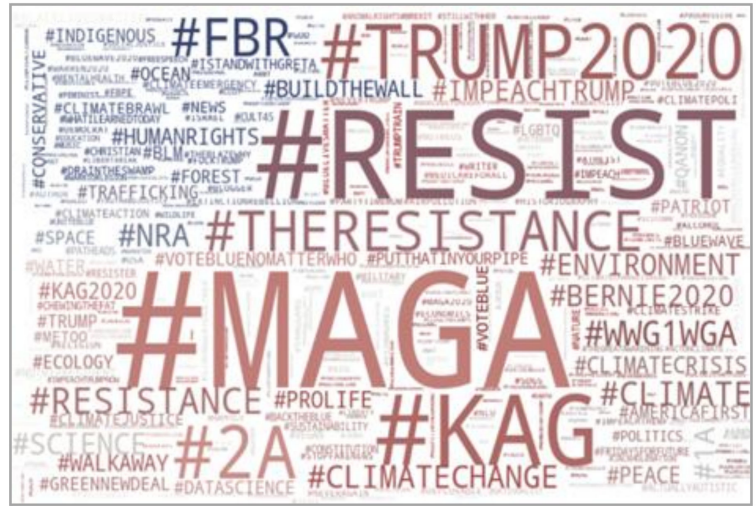

(a)

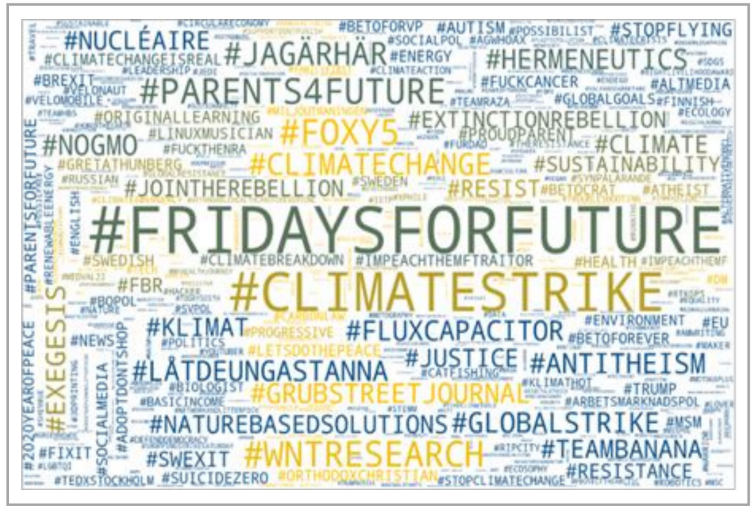

(b)

Figure 5. Comparison of Hashtag from the User Profiles of (a) the United States and (b) Sweden.

Figure 6 presents that users' occupational statuses were similar for the two countries. The most common occupations extracted from the user description for both countries were author, writer and journalist. In addition, those with jobs requiring expressiveness skills, such as artist, photographer, producer and designer were also noticeable in the dataset. Moreover, "retired" was found to provide quite a large portion of the user base. We may thus infer that a relatively large portion of Twitter's users are older than college students [10].

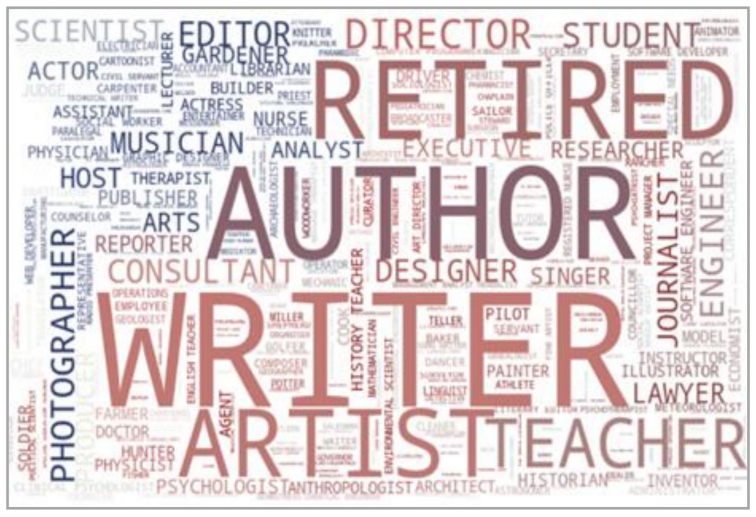

(a)

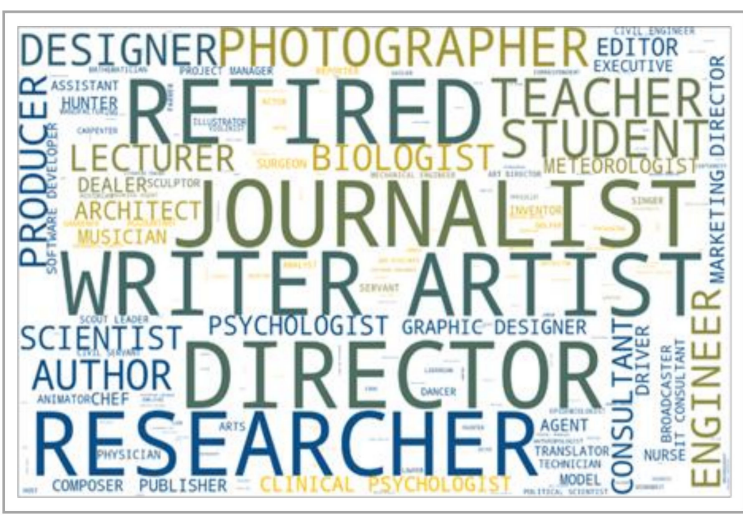

(b)

Figure 6. Comparison of occupation from the User Profiles of (a) the United States and (b) Sweden.

In total, $27.4 \%$ of tweets had URLs directing readers to the source of the information, such as news websites. As shown in Figure 7, the main link targets for US users were "The Guardian," "YouTube," and "EcoInternet"; for Swedish users, they were quite similar, but "EcoInternet" was replaced by the "FridaysForFuture" website. One interesting aspect about the sources is that the most frequent target of the links of the two countries' users was "The Guardian." This is not that surprising, because The Guardian is one of the major news platforms and has a wide reach. It is also possible that The Guardian was taking advantage of the controversy generated around Thunberg. In any case, what is interesting is that users were promoting the opinions of only one (or a few) media rather than diverse news media. Future studies are needed to explore the means by which users decide on the source of information. 


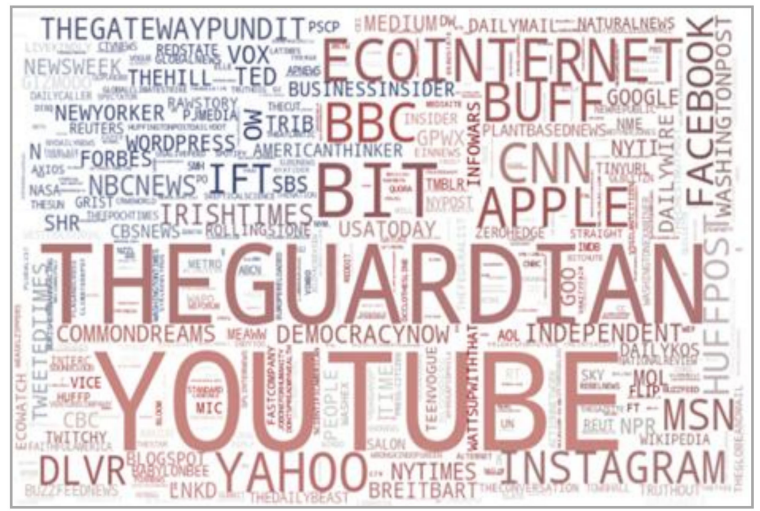

(a)

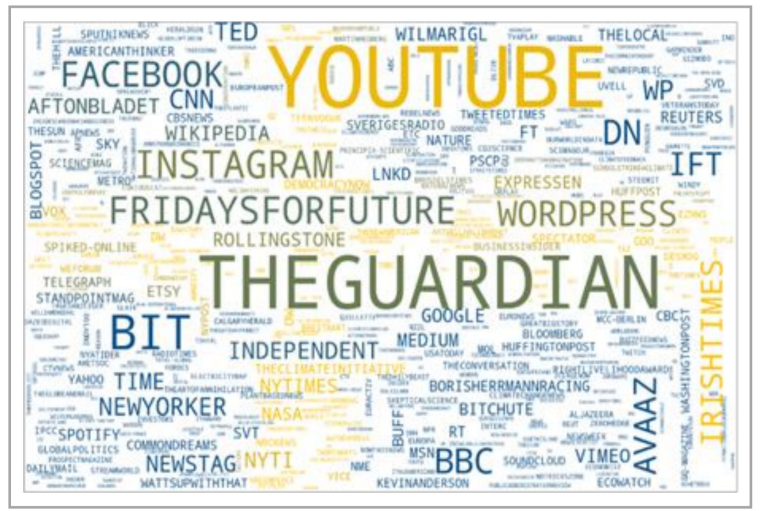

(b)

Figure 7. Comparison of information source from the User Profiles of (a) the United States and (b) Sweden.

\subsection{Addressing Influential Tweets}

When looking deeper into the 20 most frequent bigrams on a monthly basis, an interesting set of high-profile supporters and opponents appear.

- Supportive: Alexandria Ocasio-Cortez, Naomi Klein

- Against: Michael Knowles, Neil Hamilton, Arron Banks, Toby Young, Andrew Bolt, Donald Trump, Vladimir Putin

Alexandria Ocasio-Cortez is a US politician known for climate activism. She has been one of the most influential followers of Thunberg for a long time. A considerable number of negative tweets were provided by adult males.

Here are examples of such comments:

- Michael Knowles, a US political commentator, described Thunberg on TV and Twitter as "autistic" and "mentally ill."

- Toby Young, a UK Journalist, referred to Thunberg on Twitter as a "privileged daughter of Sweden's Eurovision star."

- Arron Banks, a UK businessman and political donor, tweeted in reference to Thunberg's Atlantic crossing that "Freak yachting accidents do happen in August..."

- Vladimir Putin, the Russian President, referred to Thunberg on Energy Forum as "a teen who is not informed about the complex world," (author's translation) implying that she is manipulated by adults who should be condemned.

Although some of the hostile comments were not generated on the Twitter platform, Twitter was actively used as a tool for communicating and reproducing these comments.

\subsubsection{The Most Followed Users}

The authors analyzed the characteristics of the most influential users. Doing so can help to determine how and where an issue is discussed socially.

When retweeted by another user, a tweet is expected to reach about 1000 more users, on average [37]. Given the nature of Twitter, a tweet from a user with more followers reaches more users. For tweets mentioning Greta Thunberg, the users with the highest number of followers are listed in Table 7. 
Table 7. The most followed users who mentioned Greta Thunberg in their tweets.

\begin{tabular}{cccccc}
\hline No & User Name & Field & Followers & Retweets & Likes \\
\hline 1 & Barack Obama & Politician & $110,502,216$ & 53,753 & 351,716 \\
\hline 2 & Ellen DeGeneres & Media (TV Show) & $79,080,725$ & 1036 & 9524 \\
\hline 3 & YouTube & Media (SNS ${ }^{1}$ ) & $72,102,166$ & 459 & 1840 \\
\hline 4 & The New York Times & Media (Press) & $44,585,315$ & 728 & 3549 \\
\hline 5 & CNN & Media (Press) & $43,713,122$ & 1940 & 14,923 \\
\hline 6 & Instagram & Media (SNS) & $36,214,538$ & 546 & 2750 \\
\hline 7 & Elon Musk & Entrepreneur & $29,814,753$ & 82 & 1766 \\
\hline 8 & BBC News (World) & Media (Press) & $26,242,380$ & 4413 & 16,039 \\
\hline 9 & Hillary Clinton & Politician & $26,001,043$ & 4948 & 35,535 \\
\hline 10 & The Economist & Media (Press) & $24,180,863$ & 471 & 1551 \\
\hline
\end{tabular}

By and large, media platforms and politicians comprised the majority, indicating that the traditional media and social media are mutually dependent; traditional media pursue trending issues on social media, and social media receive credit from the news authorities. Politicians also utilize the interaction between social media and traditional media with respect to trending topics in order to bring support bases together. Former Dutch prime minister Mark Rutte admitted that the interaction between old and new media is particularly attractive to politicians: "What we do on social networks leads to extra attention on television and in the newspapers" [38].

The presence of social media and television shows on the list can be understood in light of the interest that Thunberg generated from people of diverse backgrounds.

\subsubsection{The Most Shared Tweets}

The number of retweets can be a good indicator of an issue's dissemination because retweets are automatically presented to new audiences. Retweeting is a more active response than simply following or liking but also easier than creating original tweets.

Since this study tried to avoid a situation in which the news about the UN speech dominated the whole analysis, the authors compared the most shared tweets before and after that day. As stated earlier, the most shared tweet was Thunberg's own; thus, the tweets generated by her are excluded from this analysis.

Table 8 presents a list of users who generated the most shared tweets before Thunberg's UN speech. The authors categorized the users by their occupation. The "stance" of each user was manually assessed by the authors and identified as a stance to differentiate it from the sentiment analysis produced by TextBlob. It was hard to determine attitudes from some of the tweets accurately, especially when satirical nuance was included. In some cases, the target of the comment was unclear. To increase accuracy, the authors examined the context and tweet history. Although some of the news content showed bias, the authors decided not to classify the news platforms, given the nature of the media and multiple news items they deliver. The stances were classified as "supportive," "neutral," and "against." 
Table 8. The users who generated the most shared tweets before Greta Thunberg's UN speech.

\begin{tabular}{cccccc}
\hline No & User Name & Stance & Field & Followers & Retweets \\
\hline 1 & Louise Macdonald & Supportive & Charity CEO & 14,349 & 59,308 \\
\hline 2 & Barack Obama & Supportive & Politician & $110,502,216$ & 53,753 \\
\hline 3 & The Daily Show & Neutral & TV Program & $8,219,235$ & 33,319 \\
\hline 4 & Alexandria Ocasio-Cortez & Supportive & Politician & $5,882,183$ & 31,951 \\
\hline 5 & NowThis & Neutral & News & $2,473,475$ & 24,883 \\
\hline 6 & Bernie Sanders & Supportive & Politician & $8,826,467$ & 23,124 \\
\hline 7 & Wild Geerters & Supportive & Journalist & 85,730 & 21,278 \\
\hline 8 & Louise Seamster & Supportive & Professor & 3915 & 17,012 \\
\hline 9 & The Independent & Neutral & News & $2,944,290$ & 16,043 \\
\hline 10 & Rutger Bregman & Supportive & Writer & 321,612 & 14,824 \\
\hline
\end{tabular}

In general, supportive users were more likely to retweet than were antagonistic users. News media reports and television interviews were shared actively since they are credible sources, but the retweeting rank did not always match the number of followers. In addition, the occupations appeared to be diverse: politician, professor, writer, journalist and actor. These users have something in common in that they have a certain a level of influence in their respective fields and their jobs are generally considered to be those of social opinion leaders. Elite polarization fundamentally affects public opinion formation, increases the influence of party endorsements on opinions, and diminishes the influence of substantive information. [39]

Many of the retweeted contents had a similar format: comment(s) added to a news link, video clip or image. Political comments were added, both by politicians and non-politicians. Both wanted to draw the attention of their support group by actively expressing their opinions on trending issues.

Table 9 presents a list of users who generated the most shared tweets following Thunberg's UN speech. Retweet counts almost doubled after the speech, and the tweets from supportive users were shared far more often. The diversity of the influential users and the topics of much-supported opinions show interesting features.

Table 9. Users who generated the most shared tweets after Greta Thunberg's UN speech.

\begin{tabular}{cccccc}
\hline No & User Name & Stance & Field & Followers & Retweets \\
\hline 1 & Mark Humphries & Supportive & Comedian & 37,424 & 115,039 \\
\hline 2 & CNN & Neutral & News & $43,712,583$ & 83,269 \\
\hline 3 & WIRED & Neutral & Magazine & $10,413,707$ & 65,022 \\
\hline 4 & TIME & Neutral & News & $16,428,091$ & 62,114 \\
\hline 5 & Darbs & Supportive & Photographer & 416 & 62,097 \\
\hline 6 & Kyle Griffin & Supportive & Producer & 653,593 & 57,412 \\
\hline 7 & StanceGrounded & Supportive & Civil Rights Activist & 310,336 & 42,757 \\
\hline 8 & Margo Claire & Supportive & Editor & 1161 & 33,424 \\
\hline 9 & Rufus Sewell & Supportive & Actor & 52,639 & 33,327 \\
\hline 10 & Paul Joseph Watson & Against & YouTube Creator & $1,064,259$ & 33,062 \\
\hline
\end{tabular}

First, there was a change in the most shared users in terms of composition. The second, third and fourth leading users are news sources. After the United Nations speech, Thunberg made news headlines globally, and media coverage increased tremendously, with the result that the issue reached 
people who did not have an interest in climate change. Politicians disappeared from the list, and influencers from various fields emerged. The tweets of users with fewer followers also had a chance of being shared.

Second, along with the increased diversity of users, the topics of much-supported opinions shifted from climate change to other issues. Most of the tweets quoted speeches by Thunberg or news articles but their concern was not climate change. Instead, there were conflicting opinions about Thunberg herself. Opponents criticized Thunberg and her supporters for their looks, gender, ethnicity or age. Supporters criticized her opponents for their ignorance and irresponsibility while emphasizing the inspirational nature of Thunberg's bravery and way of speaking. Sometimes, however, users who appeared to be supportive also complained about her attracting all the attention, which they felt should be shared with other activists. The most shared tweet was a satirical video about adults angry at a child. It was posted by an actor who starred in it [40].

The reactions to Thunberg were increasingly polarized; again, the polarized reaction drew more attention.

Examples of most shared tweets reflecting other sources of social conflict are presented below:

- "Guys, it is not okay to want Greta Thunberg to 'lead' us."

- “... how white Americans literally import white activists from Europe because they won't listen to PoC (people of color) activists ..."

- "Along with Greta Thunberg, three young climate activists of color you should know ... "

- "I am EXTREMELY inspired by Greta Thunberg's refusal to smile or make jokes throughout all this media coverage."

\section{Conclusions}

\subsection{Conclusion and Implications}

This study examined (1) how Twitter users expressed their perceptions of and sentiments about Greta Thunberg, (2) the profiles of those who commented on Thunberg or shared tweets from or about her and her activities, and (3) how her message changed while it was spreading globally.

The sentiment analysis results from about 1.7 million tweets related to Thunberg produced both positive (e.g., Nobel Peace Prize) and negative sentiments (e.g., child abuse) about Thunberg, demonstrating that people are divided about her activities even in cyberspace. The study also found that political polarization permeated the tweets on Thunberg. Brexit was discussed in relation to her trans-Atlantic voyage. US election-related hashtags, such as \#MAGA and \#Trump2020, were found in our analysis. On the basis of the user profile analysis results, the authors identified the most followed user (Barack Obama), the user who generated the most shared tweet before Thunberg's UN speech (Louise Macdonald) and the user who generated the most shared tweet after Thunberg's UN speech (Mark Humphries), suggesting that celebrities and global leaders were commenting on, criticizing, or idolizing her in order to promote their own positions. As a result, Thunberg herself became a world-renowned figure with millions of followers.

The use of Twitter data has been a popular approach for researchers from different domains; this paper analyzes Twitter communications in relation to a social figure, a subject that has not often been studied. The authors suggest that more studies of user profiles should be conducted; it is a relatively new area in Twitter research.

The implications from this study can be summarized thus. First, social media can be a channel for connecting to opinion leaders, and issues can be disseminated much faster through a few powerful connections. Greta Thunberg admitted that the social media activities of climate movement organizations and entrepreneurs increased her exposure in a short period because they actively retweeted her message. Adults in power witnessed a teenager using social media as a direct communication channel. 
Second, those who use social media do so to encourage supportive groups in a homogeneous opinion chamber. In particular, social media provide an opportunity for minority groups to communicate with other parties directly, rather than relying on traditional media, to broadcast their events and thoughts. As we saw from the user profile analysis of the most shared tweets, a person with only a few followers can spread her/his own opinion effectively to many. Social media make the process much easier than do traditional media.

Third, the social interactions related to Greta Thunberg reflect the current forms of social conflict that occur globally. Twitter has been a political battlefield for both sides. Climate change issues are increasingly related to policy and political context. Donald Trump's re-election was unexpectedly connected to Greta in the United States, as her activities were promoted in a political context. However, the conversation also evolved to include other topics, such as gender equality, ethnicity and social class.

\subsection{Limitations and Future Study}

First, a new methodology to categorize sentiment should be considered for future studies. Even if climate change is one of the most polarizing topics in social media, almost $40 \%$ of tweets were categorized as neutral in our data. Many tweets relevant to the topic comprised retweets or reactions to events or speeches. Users may share a source because they basically agree or disagree with it. Support for a favored opinion can be treated as positive feedback [41], but accuracy can be improved by analyzing other tweets generated by the same user.

Second, tweet contents can be analyzed alongside user profiles to determine whether opinions evolve differently among different user groups. This study analyzed users' self-claimed location, the campaigns they supported and their occupations. This aspect of the study could be extended in many possible directions by subsequent research.

Future research could also include non-English tweets so that most European and Asian tweets are included. This would boost the precision level of research, particularly when macro-level data are compared. Some of the users tweeted about Thunberg in English in order to target a bigger audience, but many of their other tweets were in another language.

Author Contributions: Conceptualization, J.J.; data curation, J.J. and P.P.; formal analysis, J.J. and P.P.; methodology, J.J.; project administration, J.H.K.; software, J.J. and P.P.; Supervision, J.H.K.; writing-original draft, J.J., P.P. and D.N.; writing-review and editing, J.J., D.N. and J.H.K. All authors have read and agreed to the published version of the manuscript.

Funding: This work was supported by a National Research Foundation of Korea (NRF) grant funded by the Korean government (MIST: 2019RIHIA2101038).

Conflicts of Interest: The authors declare no conflict of interest.

\section{References}

1. Parker, T. The Greta Effect. The Perspective. Available online: http://www.theperspective.se/the-greta-effect/ (accessed on 24 January 2020).

2. Crouch, D. The Swedish 15-year-old Who's Cutting Class to Fight the Climate Crisis. The Guardian. Available online: https://www.theguardian.com/science/2018/sep/01/swedish-15-year-old-cutting-class-to-fight-theclimate-crisis (accessed on 24 January 2020).

3. Haynes, S. Now I Am Speaking to the Whole World. How Teen Climate Activist Greta Thunberg Got Everyone to Listen. Time. Available online: https://time.com/collection-post/5584902/greta-thunberg-nextgeneration-leaders/ (accessed on 24 January 2020).

4. Steer, G. 'Climate Change Is Forever'. Thousands of British Schoolchildren Walk Out in Environmental Protest. Time. Available online: https://time.com/5530374/europe-climate-change/ (accessed on 18 December 2019).

5. Kozek, B.; Ernst-Dziedzic, E. The Austrian Greens Make Their Comeback. The Green European Journal. Available online: https://www.greeneuropeanjournal.eu/the-austrian-greens-make-their-comeback/ (accessed on 24 January 2020). 
6. Frangoul, A. Coldplay's Chris Martin Says Band will not Tour its New Album due to Environment Concerns. CNBC. Available online: https://www.cnbc.com/2019/11/21/coldplay-will-not-tour-new-albumdue-to-environment-concerns.html (accessed on 18 December 2019).

7. Tait, A. Greta Thunberg: How One Teenager Became the Voice of the Planet. Available online: https: //www.wired.co.uk/article/greta-thunberg-climate-crisis (accessed on 18 December 2019).

8. Behrmann, S. 9 Things to Know about Teenage Climate Change Activist Greta Thunberg. USA Today. Available online: https://www.usatoday.com/story/news/politics/2019/09/18/greta-thunberg-6-things-knowclimate-change-activist/2358463001/ (accessed on 18 December 2019).

9. Pak, A.; Paroubek, P. Twitter as a corpus for sentiment analysis and opinion mining. In Proceedings of the LREC 2010, Valletta, Malta, 17-23 May 2010; Volume 10, pp. 1320-1326.

10. Shearer, E.; Grieco, E. Americans Are Wary of the Role Social Media Sites Play in Delivering the News. Pew Research Center. Available online: https://www.journalism.org/2019/10/02/americans-are-wary-of-therole-social-media-sites-play-in-delivering-the-news/ (accessed on 18 December 2019).

11. Broersma, M.; Graham, T. Twitter as a news source: How Dutch and British newspapers used tweets in their news coverage, 2007-2011. J. Pract. 2013, 7, 446-464. [CrossRef]

12. Lerman, K.; Ghosh, R. Information contagion: An empirical study of the spread of news on digg and twitter social networks. In Proceedings of the Fourth International AAAI Conference on Weblogs and Social Media, Washington, DC, USA, 23-26 May 2010.

13. Geva, H.; Oestreicher-Singer, G. Using Retweets when shaping our online persona: Topic Modeling approach. MIS Q. 2019, 43, 501-524. [CrossRef]

14. Bakshy, E.; Karrer, B.; Adamic, L.A. Social influence and the diffusion of user-created content. In Proceedings of the 10th ACM conference on Electronic commerce, Stanford, CA, USA, 6-10 June 2009; pp. 325-334.

15. Hansen, L.K.; Arvidsson, A.; Nielsen, F.Å.; Colleoni, E.; Etter, M. Good friends, bad news-affect and virality in twitter. In Future Information Technology; Springer: Berlin/Heidelberg, Germany, 2011; pp. 34-43.

16. Veltri, G.A.; Atanasova, D. Cliamte change on Twitter; Content, media ecology and information sharing behavior. Public Underst. Sci. 2015, 1-17. [CrossRef]

17. Peace, W.; Holmberg, K.; Hellsten, I.; Nerlich, B. Climate change on Twitter: Topics, communities and conversations about the 2013 IPCC Working Group 1 Report. PLoS ONE 2014, 9. [CrossRef]

18. Hart, P.S.; Nisbet, E.C. Boomerang effects in science communication: How motivated reasoning and identity cues amplify opinion polarization about climate mitigation policies. Commun. Res. 2012, 39, 701-723. [CrossRef]

19. Nivola, P.S.; Brady, D.W. Red and Blue Nation? Characteristics and Causes of America's Polarized Politics; Brookings Institution Press: Washington, DC, USA, 2008; Volume 1.

20. Smith, M.A.; Rainie, L.; Shneiderman, B.; Himelboim, I. Mapping Twitter Topic Networks: From Polarized Crowds to Community Clusters. Pew Research Center. Available online: https://www.pewresearch.org/internet/2014/02/20/mapping-twitter-topic-networks-from-polarizedcrowds-to-community-clusters/ (accessed on 24 January 2020).

21. Bennett, W.L.; Iyengar, S. A new era of minimal effects? The changing foundations of political communication. J. Commun. 2008, 58, 707-731. [CrossRef]

22. Talisse, R.B. Political Polarization Is about Feelings, not Facts. Available online: https://theconversation.com/ political-polarization-is-about-feelings-not-facts-120397 (accessed on 18 December 2019).

23. Llewellyn, C.; Cram, L.; Hill, R.L.; Favero, A. For Whom the Bell Trolls: Shifting Troll Behaviour in the Twitter Brexit Debate. J. Common Mark. Stud. 2019, 57, 1148-1164. [CrossRef]

24. Pang, B.; Lee, L. Opinion Mining and Sentiment Analysis. Found. Trends Inf. Retr. 2008, 2, 1-135. [CrossRef]

25. Kennedy, A.; Inkpen, D. Sentiment classification of movie reviews using contextual valence shifters. Comput. Intell. 2006, 22, 110-125. [CrossRef]

26. Koppel, M.; Schler, J. The importance of neutral examples for learning sentiment. Comput. Intell. 2006, 22, 100-109. [CrossRef]

27. Dave, K.; Lawrence, S.; Pennock, D.M. Mining the peanut gallery: Opinion extraction and semantic classification of product reviews. In Proceedings of the 12th international conference on World Wide Web, Budapest, Hungary, 20-24 May 2003; pp. 519-528.

28. Loria, S. TextBlob: Simplified Text Processing. Release ver. 0.15.2. Available online: https://textblob. readthedocs.org/en/dev/index.html (accessed on 26 March 2020). 
29. Van Rossum, G.; Drake, F.L., Jr. Python Reference Manual, Release 2.0.1. Available online: https://docs. python.org/2.0/ref/ref.html (accessed on 26 March 2020).

30. Bird, S.; Bird, I.S.; Bird, K.E.; Loper, E. Natural Language Processing with Python; O'Reilly Media, Inc.: Sebastopol, CA, USA, 2009; p. 504.

31. Araque, O.; Corcuera-Platas, I.; Ignacio, J.S.R.; Iglesias, C. Enhancing deep learning sentiment analysis with ensemble techniques in social applications. Expert Syst. Appl. 2017, 77, 236-246. [CrossRef]

32. Twitter. Available online: https://twitter.com/cnn/status/1176524220458815488?lang=en (accessed on 18 December 2019).

33. Twitter. Available online: https://twitter.com/GretaThunberg (accessed on 18 December 2019).

34. Wu, S.; Tan, C.; Kleinberg, J.; Macy, M.W. Does bad news go away faster? In Proceedings of the Fifth International Conference on Weblogs and Social Media, Barcelona, Spain, 17-21 July 2011.

35. Twitter. Available online: https://witter.com/gretathunberg/status/1167916177927991296?lang=en (accessed on 18 December 2019).

36. Heimerl, F.; Lohmann, S.; Lange, S.; Ertl, T. Word Cloud Explorer: Text analytics based on Word clouds. In Proceedings of the 2014 47th Hawaii International Conference on System Sciences, Waikoloa, HI, USA, 6-9 January 2014; pp. 1833-1842.

37. Kwak, H.; Lee, C.; Park, H.; Moon, S. What is Twitter, a social network or a news media? In Proceedings of the 19th International Conference on World wide web, Raleigh, NC, USA, 26-30 April 2010; pp. 591-600.

38. Broersma, M.; Graham, T. Social media as beat: Tweets as a news source during the 2010 British and Dutch elections. J. Pract. 2012, 6, 403-419. [CrossRef]

39. Druckman, J.; Peterson, E.; Slothuus, R. How Elite Partisan Polarization Affects Public Opinion Formation. Am. Polit. Sci. Rev. 2013, 107, 55-79. [CrossRef]

40. Twitter. Available online: https://witter.com/markhumphries/status/1177178666402365440 (accessed on 18 December 2019).

41. Banisch, S.; Olbrich, E. Opinion polarization by learning from social feedback. J. Math. Sociol. 2018, 43, 76-103. [CrossRef]

(C) 2020 by the authors. Licensee MDPI, Basel, Switzerland. This article is an open access article distributed under the terms and conditions of the Creative Commons Attribution (CC BY) license (http://creativecommons.org/licenses/by/4.0/). 